\title{
Entre el prisma discursivo y el ciberhumanismo: algunas reflexiones sobre Derechos Humanos de cuarta generación
}

Paulina Morales Aguilera Universidad Católica Silva Henríquez

Chile

Para citar este artículo: Morales Aguilera, Paulina. «Entre el prisma discursivo y el ciberhumanismo: algunas reflexiones sobre Derechos Humanos de cuarta generación». Franciscanum 169, Vol. LX (2018): 39-86.

\section{Resumen}

Actualmente se encuentra en desarrollo una cuarta generación de derechos humanos, entre cuyos contenidos se agrupa lo relativo al despliegue humano a la luz de las tecnologías de la comunicación e información en el ciberespacio. El presente artículo es una reflexión sobre dicho tema, específicamente desde dos perspectivas de lectura. Por una parte, en cuanto a las posibilidades de configuración de tales prerrogativas con base en el concepto de «derechos discursivos», a partir de los planteamientos de Jürgen Habermas, pero revisitados ahora en este nuevo escenario. Por otra, desde la mirada del ciberhumanismo, que permite enriquecer y complementar el prisma habermasiano, habida cuenta de sus limitaciones en el entorno virtual. La pregunta

\footnotetext{
Licenciada en trabajo social, Universidad Tecnológica Metropolitana (Chile); magíster en filosofía, mención axiología y filosofía política, Universidad de Chile; Doctora en filosofía, Universidad de Valencia (España). Actualmente es académica de la Universidad Católica Silva Henríquez (Santiago de Chile). Contacto: pmoralesa@ucsh.cl.
} 
por los Derechos Humanos en el contexto ciberespacial demanda tanto una relectura de los derechos ya existentes, como una dilucidación de nuevas prerrogativas en el marco de la sociedad tecnológica de hoy.

\title{
Palabras clave
}

Derechos humanos, cuarta generación, prisma discursivo, J. Habermas, ciberhumanismo.

\section{Between the discursive approach and cyberhumanism: some reflections about fourth generation human rights}

\begin{abstract}
A fourth generation of human rights is actually under development that includes, among others, the content of human deployment in light of communication and information technologies within the cyberspace. This article is a reflection of this matter, specifically from the perspective of two readings. On the one hand, as to the possibilities of configuring such prerogatives based on the concept of «discursive rights», from the statements of Jürgen Habermas, but now revisited in this new scenario. On the other hand, from the view of cyberhumanism, which allows to enrich and complement Habermas' prism, given its limitations in the virtual environment. The question for the human rights in the cyberspace demands both a re-reading of existing rights and an elucidation of new prerogatives within the framework of today's technological society.
\end{abstract}

\section{Keywords}

Human rights, fourth generation, discursive approach, J. Habermas, cyberhumanism. 


\section{Introducción}

El presente artículo busca plantear una reflexión sobre derechos humanos en el nuevo escenario que ha ido emergiendo a raíz de los innumerables avances científicos y tecnológicos de las últimas décadas. Cuestiones como las redes y tecnologías de la información y la comunicación, las biotecnologías, el espacio virtual, son todos ellos nuevos ámbitos que, en relación específica con los derechos humanos, pueden ser leídos al menos en tres sentidos. Primero, se constituyen como entornos emergentes en los cuales se juegan las posibilidades de concreción de los derechos humanos ya instituidos hasta el momento. Segundo, evidencian el surgimiento de nuevas prerrogativas, en virtud de las nuevas realidades que encarnan. Esto es lo que algunos autores han denominado derechos humanos de cuarta generación ${ }^{1}$. Tercero, plantean nuevos y diversos desafíos a la reflexión sobre derechos humanos, especialmente en torno a uno de sus elementos o idea-fuerza crucial: la dignidad humana.

Frente a ello, las posibilidades de lectura son numerosas. Mas, reconociendo la imposibilidad de abarcarlas todas, el presente artículo se plantea dos grandes objetivos. Por una parte, analizar la factibilidad de configuración del concepto de «derechos discursivos» como parte de los derechos humanos de cuarta generación, a la luz del pensamiento de Jürgen Habermas y más allá de este. Cabe precisar que este autor no utiliza dicho término, por tanto, lo relativo al mismo es parte de esta propuesta de reflexión. Con este fin se propondrá

Cierto es que la denominación y el modelo mismo de generaciones de derechos humanos han sido cuestionados por algunos autores (David Sánchez, «Sobre el concepto de historización. Una crítica a la visión sobre las de-generaciones de derechos humanos», Praxis 67 (2011): 9-22; José Martínez de Pisón, «Las generaciones de derechos humanos», en Constitución y derechos fundamentales, coord. Jerónimo Betegón, Francisco Javier Laporta, Juan Ramón Páramo y Luis Prieto Sanchís, 409435 (Madrid: Centro de Estudios Constitucionales, 2004), entre otros). Pero no se puede desconocer que, más allá de los apelativos, están surgiendo nuevas prerrogativas asociadas a la condición humana en la sociedad tecnológica actual, como también exigencias en torno a relecturas de los derechos ya existentes. Así, cabe precisar que en estas líneas no se abordará el debate respecto a las generaciones, pues parten del reconocimiento de la necesidad de reflexionar sobre este nuevo marco como una realidad ya presente que demanda su abordaje desde una perspectiva de derechos humanos, más allá de lo relativo a denominaciones. 
una caracterización de los derechos discursivos en tanto derechos humanos de cuarta generación en el contexto tecnológico actual, a la vez que se revisarán las posibilidades de extensión y limitaciones de dicho concepto. El supuesto que subyace a este primer objetivo apunta a reconocer las posibilidades de visualizar, desde la óptica habermasiana, un nuevo conjunto emergente de derechos humanos en la era tecnológica actual, empero, con algunas limitaciones que demandan nuevos referentes para la comprensión y fundamentación de tales prerrogativas.

Tras lo anterior, un segundo objetivo se encamina a proponer el ciberhumanismo como una perspectiva capaz de complementar la mirada sobre derechos discursivos, en virtud de su potencial para hacer frente a algunas restricciones que evidencia el enfoque de Habermas. En ambos casos, lo que se busca de forma transversal es contribuir al debate sobre derechos humanos en la actualidad, desde una consideración basal: la condición tecnológica de la sociedad de hoy constituye un marco indiscutible e ineludible escenario de despliegue de lo humano en el mundo.

Ahora bien, ¿qué es lo que conforma o compone esta cuarta generación de derechos humanos? La respuesta no es unívoca. La literatura sobe el tema no refleja un consenso al respecto. Más aún, no es todavía abundante dicha producción como para asentar una noción nítida de lo mentado al recurrir al concepto de derechos humanos de cuarta generación ${ }^{2}$. Empero, reconociendo algunos trazos comunes, en este artículo se propone una comprensión de dicho conjunto de prerrogativas como articuladas en torno a un elemento definitorio o identitario: la presencia e influencia decisivas de la tecnología en diversos campos del quehacer humano. En virtud de esto, una posible

2 Si hubiera que identificar un período de tiempo asociado, puede decirse que el tema de los derechos humanos de cuarta generación ha comenzado a desarrollarse en los últimos veinte años, de forma paulatina, a diferencia de lo que ocurre con las anteriores generaciones, cuyo desarrollo, tanto cuantitativo como cualitativo es de más larga data. 
tipología de los derechos humanos de cuarta generación daría pie a dos grandes ámbitos, a saber:

a. Un primer conjunto agruparía todo el campo de prerrogativas que emergen a partir del escenario de las nuevas tecnologías de la comunicación y la información en el ciberespacio, que requieren también de una regulación en términos de deberes y derechos.

b. Otro subgrupo remitiría a derechos relativos a un nuevo estatuto jurídico para la vida humana como consecuencia del desarrollo de nuevas tecnologías biomédicas, que inciden en su conservación, extensión y producción misma.

Como se puede observar, se trata de esferas de derechos en los cuales la tecnología ha supuesto grandes modificaciones en sus formas de expresión en los campos a los que remiten. Dada la inmensidad que supone el abordaje de cada uno de ellos, en el presente artículo se centrará la mirada en lo concerniente al primer grupo de prerrogativas.

En tal dirección, una obra que vino a recoger estas preocupaciones apareció en 1999, bajo la coordinación de Graciano González y se titulaba Derechos humanos: la condición humana en la sociedad tecnológica. En este libro diversos autores exponían sus ideas en torno al tema aglutinante, a partir de una consideración inicial: el mundo tecnológico es el «lugar de inserción» del discurso sobre derechos humanos en la actualidad, especialmente en su vertiente informática, en donde Internet ha supuesto un cambio sustancial en las formas de interacción que trascienden ahora -con mucholos espacios materiales y cara a cara, para situarse en una esfera virtual de dimensiones y posibilidades inconmensurables, quizás aún insospechadas y por cierto altamente debatibles.

No obstante lo reciente de esta discusión, es interesante advertir una consideración visionaria y señera al respecto, cuando -en 1939Ortega publica su famoso texto Meditación de la técnica, en donde advierte que «uno de los temas que en los próximos años se va a 
debatir con mayor brío es el del sentido, ventajas, daños, y límites de la técnica» ${ }^{3}$. Junto con esto, su planteamiento de fondo apuntará a la consideración de la técnica como una «sobrenaturaleza» para el hombre, dado que no se trata de que el hombre se adapte a su medio, sino al contrario, de que adapta su medio a su vida con miras a la satisfacción de sus necesidades, en donde la técnica emerge como el conjunto de «reformas» que el hombre impone a la naturaleza para el cumplimiento de dicho fin, pero en la forma de una trascendencia del mismo. Esto, porque «la técnica es la reforma de la naturaleza, de esa naturaleza que nos hace necesitados y menesterosos, reforma en sentido tal que las necesidades quedan a ser posible anuladas por dejar de ser problema su satisfacción $»^{4}$. Estas ideas preclaras sin duda están presentes en la reflexión actual sobre derechos humanos de cuarta generación, pues como se verá la relación de los seres humanos con las tecnologías no se expresa al modo de un entrar y salir de las redes en el ciberespacio, sino en la forma de un vivir en ellas cotidianamente.

Ahora bien, en términos formales, el presente artículo se estructura en base a tres grandes apartados. El primero de ellos aborda la propuesta de configuración de unos «derechos discursivos» a partir de los planteamientos de Jürgen Habermas, en donde destacan aspectos como: su comprensión de un sistema de los derechos, la centralidad del espacio público o la responsabilidad y corresponsabilidad de los participantes que en él se despliegan. La segunda parte se ubica como el punto de transición desde el prisma discursivo habermasiano al ciberespacio en materia de derechos humanos. En el tercer apartado se aborda con propiedad la perspectiva ciberhumanista, en tanto propuesta de una ética para el habitante de la sociedad tecnológica de hoy. Finalmente, a modo de corolario, se incorporan algunas referencias en torno a una

3 José Ortega y Gasset, Ensimismamiento y alteración. Meditación de la técnica y otros ensayos (Madrid: Alianza, 2014), 57.

4 José Ortega y Gasset, Ensimismamiento y alteración, 66 
declaración de derechos humanos en el ciberespacio, que permite visualizar con mayor claridad la emergencia de algunas prerrogativas específicas en relación con lo expuesto en las líneas precedentes.

\section{Derechos discursivos a la luz del pensamiento de $\mathbf{J}$. Habermas}

\subsection{Estructura del «sistema de los derechos»}

Como se conoce, el tema de los derechos humanos ha estado presente, con mayor o menor fuerza, en toda la obra habermasiana. Trazos de ella se encuentran tempranamente en Historia y crítica de la opinión pública, de 1962, en donde se apunta a la vinculación específica entre publicidad y derechos fundamentales. Este tópico seguirá apareciendo de forma más bien fragmentaria en sus obras posteriores, hasta que en la década de los noventa comienza a cobrar un espacio protagónico en sus reflexiones políticas sobre democracia, Estados nacionales y escenarios transnacionales. De esto dará cuenta, primero, la obra que marca un hito en términos de un abordaje contundente de la temática de los derechos: Facticidad y validez, original de 1992. A ella le seguirán La inclusión del otro (1996) y, dos años más tarde, La constelación postnacional ${ }^{5}$.

En efecto, es en Facticidad y validez en donde el autor germano propone y desarrolla en profundidad lo que se conocerá como el «sistema de los derechos», que básicamente apunta a un conjunto de prerrogativas susceptibles de reconocimiento mutuo entre los miembros de una comunidad política. Dicho sistema se organiza con base en cinco grandes categorías de derechos ${ }^{6}$, que son:

5 Una revisión exhaustiva del tema de los derechos humanos en Habermas puede encontrarse en: Paulina Morales, «Habermas y los derechos humanos: posibilidades y limitaciones de una reflexión», Convergencia 65 (2014): 13-37. Paulina Morales, «El concepto de dignidad humana en Habermas: algunas implicancias para su reflexión sobre la «utopía realista» de los derechos humanos», Agora Philosophica 29 (2014): 90-116.

6 No se debe confundir estas categorías habermasianas con lo que en la literatura sobre derechos humanos se denomina «generaciones». 
1. Derechos fundamentales que resultan del desarrollo y configuración políticamente autónomos del derecho al mayor grado posible de iguales libertades subjetivas de acción.

2. Derechos fundamentales que son el resultado del desarrollo y configuración políticamente autónomos del status de miembro de la asociación voluntaria que es la comunidad jurídica.

3. Derechos fundamentales que provienen directamente de la accionabilidad de los derechos, es decir, de la posibilidad de reclamar judicialmente su cumplimiento, y del desarrollo y configuración políticamente autónomos de la protección de los derechos individuales.

4. Derechos fundamentales a participar con igualdad de oportunidades en procesos de formación de la opinión y la voluntad comunes, en los que los ciudadanos ejerzan su autonomía política y mediante los que establezcan derecho legítimo.

5. Derechos fundamentales a que se garanticen condiciones de vida social, técnica y ecológicamente aseguradas en la medida en que ello sea necesario para un disfrute en igualdad de oportunidades de los derechos civiles explicitados en las categorías precedentes ${ }^{7}$.

En torno a este esquema, valgan unas breves precisiones ${ }^{8}$. Primero, las categorías 1), 2) y 3) se centran fundamentalmente en la defensa de la autonomía privada de los sujetos jurídicos. Segundo, la categoría 4), es la que permite, posteriormente, el tránsito hacia una consideración ampliada de dichos sujetos, ya no solo como destinatarios del derecho sino como autores del mismo; lo que se releva aquí es la autonomía pública de los sujetos jurídicos. Tercero, la categoría 5) se ubica como transversal a todas las anteriores y enfatiza la noción de igualdad, especialmente teniendo en cuenta las desigualdades que es posible advertir en los campos social, técnico y ecológico.

7 Jürgen Habermas, Facticidad y validez (Madrid: Trotta, 2008), 188-189

8 Para un análisis exhaustivo de este sistema, ver las publicaciones indicadas en nota al pie número 6 . 


\subsection{Derechos discursivos como derechos humanos de cuarta generación: posibilidades de configuración en la era tecnológica}

Lo que pueda denominarse «derechos discursivos» a la luz de los planteamientos habermasianos, deberá necesariamente situarse en el escenario de un espacio público virtual configurado al amparo de las nuevas tecnologías de la comunicación y la información, las cuales tienen alcance mundial y trascienden por tanto los márgenes locales, regionales y nacionales. Ante la abundancia de medios y canales en el ciberespacio, algunos autores han comenzado a vislumbrar y delinear lo que podría constituirse como una cuarta generación de derechos humanos ${ }^{9}$. Los énfasis en estas diferentes iniciativas se dirigen a diversos aspectos.

Por una parte, a la reflexión sobre la condición humana en la era tecnológica, reconociendo que «el desarrollo social y moral del ser humano no ha sido nunca opaco al desarrollo de las realidades técnicas científicas $»^{10}$. En Habermas esto se encontraría presente en la quinta y última categoría de su sistema de los derechos, que tal como se señaló apuntaba a prerrogativas capaces de garantizar «condiciones de vida social, técnica y ecológicamente aseguradas en la medida en que ello sea necesario para un disfrute en igualdad de oportunidades de los derechos civiles explicitados en las categorías precedentes» ${ }^{11}$. Lo que se muestra, más específicamente, es la referencia al vínculo entre técnica y práctica política, cuestión que remite, a su vez, al espacio público como campo

Aquí destacan los trabajos de: Robert Gelman, «Draft Proposal: Declaration of Human Rights in Cyberspace», 1997. Texto no editado, consultada en mayo 25, 2015, www.be-in.com/10/rightsdec. html; Graciano González, coord. Derechos Humanos: La condición humana en la sociedad tecnológica (Madrid: Tecnos, 1999); Javier Bustamante. «Hacia la cuarta generación de derechos humanos: repensando la condición humana en la sociedad tecnológica», Revista Iberoamericana de Ciencia, Tecnología, Sociedad e Innovación 1 (2001): s/p., consultada en abril 23, 2015, www.oei.es/revistactsi/ numero1/bustamante.htm; Emilio Suñé, «Declaración de derechos del ciberespacio», 2008, texto no editado, consultada en mayo 28, 2015, http://190.7.110.123/pdf/7_convencionesDerechoInformatico/ documentacion/conferencias/Los_Derechos_Humanos_en_el_Ciberespacio.pdf; Robin Mansell, «Introduction. Human rights and equity in Cyberspace», en Human Rights in the Digital Age, ed. Andrew Murray y Mathias Klang (London: The Glasshouse Press, 2009). Ver detalles en bibliografía.

10 Javier Bustamante. «Hacia la cuarta generación de derechos humanos: repensando la condición humana en la sociedad tecnológica».

11 Jürgen Habermas, Facticidad y validez, 189. 
de despliegue de deliberaciones compartidas sobre el particular. En este sentido, el autor opta por visualizar este problema teniendo como marco de referencia el proceso de formación de la voluntad política, en virtud de lo cual le preocupa cómo pueda restituirse la capacidad de disposición técnica al ámbito del consenso de los ciudadanos. Por cierto, se trata de una preocupación de viejo cuño para el autor, que ya hacia fines de los años 60 se preguntaba, en relación con la racionalidad de la ciencia y la técnica si es que acaso «ìno contendrá ya en su seno, en lugar de reducirse, como pretende, a las reglas de la lógica y de la acción controlada por el éxito, un a priori material surgido históricamente y por eso también superable históricamente?» ${ }^{12}$. En este marco cabe plantear nuevas reflexiones en torno a «la forma en que el ciberespacio está siendo experimentada por la gente en los contextos muy dispares de su vida cotidiana» ${ }^{13}$; la reflexión sobre el fenómeno mismo de la acción comunicativa orientada al entendimiento en la era digital, entre otros, tiene pleno sentido y pertinencia.

Junto con ello, la referencia al escenario tecnológico en materia de derechos humanos se vincula también con las posibilidades de mayor transparencia de la acción pública por parte de los gobiernos y en general de todas las entidades -tanto públicas como privadas- que no pueden ya sustraerse a la mirada escrutadora de una ciudadanía virtual en alerta respecto de altos estándares sobre la materia. En este marco, la democracia emerge como un régimen también supeditado a este ejercicio fiscalizador virtual, a la vez que se enfrenta a nuevas formas de profundización por medio de recursos tecnológicos antes desconocidos ${ }^{14}$. Así, los derechos discursivos podrían ser visualizados no solo como facultades en sí mismas, sino a la vez como condición para el ejercicio de los demás derechos.

14 Un interesante debate a este respecto es el que presenta Bustamante en su artículo «żQué puede esperar la democracia de internet? Una reflexión sobre la crítica de Langdon Winner al poder político transformador de la tecnología», Argumentos de razón técnica, 7 (2004): 13-49, consultada en julio 22, 2015, http://institucional.us.es/revistas/argumentos/7/art_1.pdf. 
Otro elemento que destaca son las numerosas afinidades entre esta cuarta generación de derechos humanos en formación y la inspiración original que dio vida a la Declaración Universal de los Derechos Humanos de 1948. Así lo refleja, entre otros, la propuesta de Gelman ${ }^{15}$ en torno a una Declaración de Derechos Humanos en el Ciberespacio $^{16}$, en donde se precisa desde el inicio que es justamente ese documento señero el que ha inspirado su formulación.

Junto con ello, los derechos humanos de cuarta generación impelen a reflexionar sobre nuevas configuraciones y comprensiones acerca de conceptos diversos como espacio público, comunicación, libertad de expresión, entre otros. La «red [internet] aparece así como uno de los escenarios donde se dirime una de las más decisivas batallas por la libertad de expresión y, por ende, por los derechos humanos en general ${ }^{17}$. El espacio público mismo, en tanto, no puede ya ser entendido solo como nacional o trasnacional sino también como virtual, en cuyo marco surgen nuevos puntos que demandan atención, como el papel y/o posicionamiento de las instituciones y de los ciudadanos en dicho espacio.

Teniendo en cuenta todo lo expuesto previamente, y articulando lo relativo a la literatura sobre derechos humanos con el prisma discursivo de Habermas, es posible esbozar un primer conjunto de rasgos característicos de los derechos discursivos, entre ellos:

i. Se trataría de derechos dotados de una bidimensionalidad individual y colectiva a la vez. Puede ser reclamados tanto a título individual como grupal, mas en su origen y forma de expresión remiten a la intersubjetividad propia de los procesos comunicativos.

ii. Estarán, por tanto, enmarcados siempre en procesos discursivos y/o comunicativos, presenciales o virtuales.

15 Robert Gelman, «Draft Proposal: Declaration of Human Rights in Cyberspace».

16 Lo relativo a esta declaración será retomado como corolario del presente artículo.

17 Javier Bustamante. «Hacia la cuarta generación de derechos humanos: repensando la condición humana en la sociedad tecnológica». 
iii. Responden en su télos a la necesidad de consenso frente a la diversidad de opiniones, opciones y cosmovisiones existentes entre los seres humanos en las sociedades plurales de hoy.

iv. Tienen un marcado énfasis en la noción de co-responsabilidad solidaria que se acuñara desde la ética del discurso, dado el fuerte cariz intersubjetivo de estos derechos.

v. Reafirman la noción de dignidad kantiana -el hombre como fin en sí mismo-, dadas las posibilidades de instrumentalización de la vida humana a partir del desarrollo de nuevas tecnologías. La dignidad humana constituye el núcleo moral de los derechos humanos.

\subsection{Posibilidades y limitaciones del prisma habermasiano sobre derechos en la sociedad tecnológica de hoy}

No obstante el esbozo presentado en el acápite anterior, los derechos discursivos necesariamente suponen una revisión, complementación y en algunos casos superación, de las consideraciones habermasianas, para incorporar nuevos elementos que nutran esta configuración. Entre ellos, primero, está el hecho de que romperían con la dualidad individuo/sociedad, dado que -especialmente en el marco del ciberespacio-se desdibujan márgenes, obligaciones y consideraciones propias de demarcaciones como los Estados nacionales u otras formas de organización política. Así, ante la emergencia de una nueva ciudadanía «asistimos a la aparición de nuevos valores, derechos y estructuras sociales que se encuentran actualmente en un período de incubación [...] cuyo criterio de pertenencia no es el territorio, ni la lengua compartida, sino un nuevo modelo de sociedad» ${ }^{18}$.

Segundo, la consideración de estos derechos como procesos discursivos en sentido habermasiano es, por cierto, una aseveración

18 Javier Bustamante, «Los derechos humanos de cuarta generación y sus implicaciones en la sociedad contemporánea», 2012, 5, consultada en enero 18, 2016, www.academia.edu/4483700/ Los_derechos_humanos_de_cuarta_generaci\%C3\%B3n_y_sus_implicaciones_en_la_sociedad_ contempor\%C3\%A1nea_2012_. 
dotada de una fuerte carga normativa. En efecto, es preciso diferenciar entre un nivel descriptivo en el cual las interacciones en el ciberespacio se expresan, muchas o la mayor parte de las veces no siguiendo ciertos presupuestos propios de las formas comunicativas tal como las pensara Habermas hace ya varias décadas, y un nivel normativo en el cual dichas precondiciones debiesen estar presentes (porque se anticiparían contrafácticamente, sostenía el germano). Empero, la distinción entre la «situación real» y la «situación ideal de habla» pierde nitidez y exige la incorporación de una situación virtual de habla, en donde, sin embargo -esta es la expectativa de estas líneas- pudieran incorporarse algunas delimitaciones a partir del prisma discursivo y, más allá de este, en relación con el ciberhumanismo.

En tercer lugar, es necesario problematizar la orientación al consenso, para que abra paso también a la opción del disenso, que parece ser justamente uno de los potenciales que ofrecen las amplias y numerosas redes de comunicación e información desplegadas en el ciberespacio. Esta plataforma permite el despliegue de interacciones, emisiones y discusiones de amplio espectro, en tiempo real, y con ilimitado número de participantes. Frente a esto, las posibilidades de consecución de consenso son claramente menores. Más aún, quizás una de las riquezas de estos nuevos espacios virtuales sea justamente el permitir la expresión de una diversidad de opiniones y de una pluralidad que en los espacios comunicativos y de información anteriores no eran posibles, o no a la escala actual. Empero, la búsqueda de consenso emerge renovada en este nuevo escenario en relación con la necesidad de acordar ciertos mínimos compartidos para que tenga sentido seguir hablando de interacciones comunicativas y de posibilidades de diálogo y comprensión de lo que se dice en el ciberespacio; todo lo opuesto a lo que se denomina un diálogo de sordos.

Como cuarto elemento, es claro que la noción de corresponsabilidad solidaria tan característica del prisma discursivo se complejiza en el 
ciberespacio y requiere de una relectura. Esto por varias razones, entre ellas:

- Porque ya no se trata de interacciones cara a cara, en donde los hablantes se conozcan y puedan constatar -o al menos suponerla disposición a responsabilizarse por las propias emisiones.

- Porque, ligado con lo anterior, en el ciberespacio muchas de las interacciones o intercambios están dados por la condición de anonimato de los participantes, o en ocasiones de identidades falsas.

- Porque parece ser que el ciberespacio es justamente percibido como un espacio de expresión e interacciones exento de contenido normativo, donde no hay reglas que impliquen sanciones para quienes las incumplen. Esto está dado por la condición de virtualidad misma que supone el ciberespacio, como también en razón de que el espacio virtual trasciende con mucho los márgenes de los Estados nacionales. ¿Quién es responsable, entonces, de la regulación de los mensajes y emisiones en el ciberespacio? ¿Cómo se puede responsabilizar a quienes se comportan en él de manera inadecuada (ofensiva, descalificadora, violenta, por ejemplo)? ${ }^{19}$. ¿Qué responsabilidades deben asumir los sujetos cuando interactúan en el ciberespacio? Por cierto, se está pensando acá en mayores cuotas de responsabilidad que la asociada a cautelar condiciones mínimas de seguridad informática, especialmente frente a fenómenos como: diseminación de virus, robos de información personal, etc.

Parece ser que la noción de corresponsabilidad se vuelve altamente problemática en el ciberespacio. Pero, asimismo, altamente necesaria, por lo cual no resulta posible abordar este aserto desde el desaliento y el inmovilismo. De hecho, la idea misma de pensar el concepto de derechos discursivos, o de recurrir a los aportes del 
ciberhumanismo, refuerzan que el camino no es el de la resignación sino el de la acción al respecto.

Ahora, otro elemento que queda en jaque en relación con el tema de la responsabilidad apunta a lo siguiente: si se establece la presencia de determinados derechos, consecuentemente debe identificarse a los responsables de satisfacer tales derechos. Entonces, si se asume la existencia de derechos discursivos, o incluso -más allá de este término- de derechos en el ciberespacio, żquién debe responder por ellos? Retrotrayéndonos al desdibujamiento en el ciberespacio de la separación individuo/sociedad, ¿̇es que entonces serían los propios individuos los responsables de responder por sus emisiones e interacciones virtuales? Puede ser un camino de respuesta, pero es necesario remitir también a la responsabilidad de las empresas dueñas de las redes y plataformas de interacción virtual, que deberán -en algunos casos ya lo están haciendo- establecer regulaciones para quienes operan en ellas.

¿Habrá, sin embargo, responsabilidad de los Estados nacionales al respecto? Esta pregunta resulta compleja de responder, pero plantea interesantes posibilidades de respuesta. En efecto, los Estados no pueden desentenderse del tema; habrán de establecer legislaciones pertinentes y colaborar también en regulaciones internacionales sobre la materia. En este sentido, la propuesta de Suñé es mucho más precisa al respecto ${ }^{20}$. Propone, por una parte, la creación de un "Ombudsman del Ciberespacio», en relación con la necesidad de establecer mecanismos de garantía de derechos en esta esfera. Por otra, sugiere la constitución de un «Tribunal de los Derechos del Ciberespacio», orientado a dirimir conflictos en materia de derechos en este ámbito. Claramente, medidas como estas requerirían del concurso activo de los Estados nacionales, entendiendo no obstante que deben trascender a ellos dado el cariz supranacional de ambas figuras propuestas. Junto con esto, este autor defiende además la

20 Emilio Suñé, «Declaración de derechos del ciberespacio». Las propuestas de este autor surgen como respuesta a la propuesta de declaración sobre la materia de R. Gelman, antes mencionada. 
necesidad de generación de un «poder constituyente» por parte de los «ciberciudadanos», otorgando a estos un protagonismo enorme, ya no solo en términos de sus posibilidades de interactuar en el ciberespacio, sino también de asumir mayores cuotas de autonomía y responsabilidad en ello.

Finalmente, si la noción de derechos discursivos configurada hasta el momento implica relevar el valor de la dignidad humana, se estaría diciendo que dicho status es en sí mismo un límite a las emisiones discursivas. Mas en el ciberespacio resulta compleja su concreción, entre otros en razón de lo que se señalaba anteriormente sobre el anonimato que permite la participación en redes y plataformas virtuales, como también dadas las inconmensurables dimensiones de estas. Las propuestas de Suñé buscan aportar al respecto. La convicción de estas líneas es que la dignidad humana resulta irrenunciable y debe ser repensada en este nuevo escenario. Las posibilidades de regulación frente a ofensas a la dignidad y la honra de las personas, que muchos Estados han incorporado en sus respectivas legislaciones nacionales, en el terreno virtual son aún un enorme camino por recorrer, pero son ya un camino. Hay también antecedentes interesantes en casos de juicios frente a grandes empresas como Google aduciendo el denominado derecho al olvido, en razón del cual algunos particulares -sentencia judicial mediante- han exigido a esta plataforma borrar ciertos contenidos falsos o difamatorios. Ligado a esto se encuentra todo el campo del manejo de datos y resguardo de información de millones de cibernautas, en donde el debate en torno a la privacidad emerge y se renueva permanentemente en este nuevo escenario. Suñé ha llegado a plantear incluso la necesidad de establecer un "Habeas Data», en tanto forma de garantía y control por parte de los ciudadanos sobre su información personal.

Como se puede advertir, queda mucho por hacer en términos de cautelar la dignidad humana en el ciberespacio. En esta senda, una precisión nutritiva podría estar dada por la diferenciación que establece 
Habermas entre «dignidad de la vida humana» $\mathrm{y}$ «dignidad humana» ${ }^{21}$. Cierto es que esta distinción surge al calor de sus reflexiones sobre la eugenesia frente al desarrollo de las biotecnologías, en su obra El futuro de la naturaleza humana, pero bien puede extrapolarse al campo del desarrollo ciberespacial. Así, con la formulación «dignidad de la vida humana» se remite al status de persona que es inherente a cada ser humano y en virtud de lo cual justamente se le pueda atribuir una especial dignidad. La segunda, -«dignidad humana»- refiere a un sentido universal de respeto con que deben ser tratados los seres humanos en consideración con la igualdad que comparten en tanto tales. Tal diferenciación refiere, a su vez, a esferas distintas desde las cuales emerge cada premisa. De esta forma, la primera de ellas tiene un carácter ontológico en tanto remite a lo que podría denominarse un «ser del hombre»; la segunda, posee un carácter ético en cuanto definiría un «deber ser» para con este. Como bien se reconoce, «entre ambas constituirían, por su carácter a priori, un verdadero sistema de referencia moral desde el cual se hace posible establecer sucesivas y diversas aproximaciones a la realidad humana» ${ }^{22}$.

\section{Transición desde el espacio público habermasiano al ciberespacio}

Como se conoce, la noción de espacio público forma parte de aquellas ideas identitarias dentro del pensamiento de Habermas. Luego, la vinculación entre derechos y lo público como espacio de despliegue de deliberaciones ha estado presente desde los inicios de su obra. Como el propio autor lo precisa, «la esfera pública como el espacio del trato comunicativo racional de unos con otros es el tema del que me he ocupado a lo largo de toda una vida. De hecho, la tríada conceptual de esfera pública, discurso y razón ha dominado mi

21 Jürgen Habermas, El futuro de la naturaleza humana. Hacia una eugenesia liberal (Barcelona: Paidós, 2002), 54.

22 Raúl Villarroel, Interesarse por la vida. Ensayos bioéticos y biopolíticos (Santiago: Universitaria 2014), 51 . 
trabajo científico y mi vida política $»^{23}$. ¿ Resulta posible situar dicha tríada, empero, en el actual contexto ciberespacial? Claramente, no es factible brindar una respuesta definitiva a dicha interrogante. En buena medida porque esas nociones son justamente las que se encuentran en jaque o requieren ser revisitadas desde la óptica de los derechos discursivos en el ciberespacio. Evidentemente, y este será uno de los mayores tránsitos, el concepto de espacio público habermasiano deberá ser extendido al de espacio virtual si es que se pretende defender su pervivencia en el escenario ciberespacial, algo no fácilmente traducible.

Intentando una delimitación conceptual al respecto, en lo que sigue se abordarán algunos rasgos característicos de la idea de espacio público en Habermas, para ir analizando a la luz de cada una de ellas sus posibilidades de traducción desde una óptica de derechos discursivos en el ciberespacio.

Primero, el espacio público en Habermas es central en el proceso de formación de la opinión y la voluntad políticas, imprescindible a su vez para la concreción de una política deliberativa, como denomina este autor a su configuración sobre democracia ${ }^{24}$. Como se conoce, dicho proceso puede correr por dos carriles diferenciados: uno de carácter formal y otro informal. El primero remite a «aquellas deliberaciones ya reguladas por procedimientos democráticos y orientadas a la toma de decisiones, mientras que la segunda remite a los procesos espontáneos de formación de la opinión en el espacio público-político, en donde la sociedad civil tiene un espacio de expresión privilegiado» ${ }^{25}$. En el caso de un espacio público virtual, lo que primaría en él sería la dimensión informal, en tanto espacio espontáneo de opiniones. Aunque potencialmente podría contribuir a los procesos de formación y la voluntad políticas, es todavía esta tarea un campo por explorar, aunque

23 Jürgen Habermas. Entre naturalismo y religión (Barcelona: Paidós, 2006), 20.

24 Cf. Jürgen Habermas, Facticidad y validez. Madrid: Trotta, 2008

25 Paulina Morales, «Hacia intervenciones sociales democratizantes: aportes desde el prisma discursivo de Jürgen Habermas», Trabajo Social 83 (2012): 11. 
sin duda ya se ha constituido como un espacio diverso de emisiones e interacciones que pueden responder a fines también muy distintos (entretención, información, vinculación, etc.).

Unido a lo anterior, Habermas apuesta por la institucionalización de dichos procedimientos y presupuestos comunicativos, como asimismo el libre fluir e interaccionar de deliberaciones y opiniones. A esto apunta con la idea de vincular los planos formal e informal en que se despliegan las interacciones en el espacio público, asumiendo que ninguno de los dos por sí solo es capaz de contener y encauzar las emisiones y demandas de la ciudadanía. Así, «los procesos institucionalizados (formales) dependen de las aportaciones provenientes del espacio público -[también entonces del espacio público virtual]- en la forma de "opiniones públicas informales", generadas espontáneamente. A ello se suma, en dirección inversa, -esto es, desde el plano formal hacia el informal-, la necesidad del espacio público de contar con una "base social" conformada por un conjunto de derechos de ciudadanía plenamente vigentes y actuantes» ${ }^{26}$. Con razón, ha llamado Cortina a estos dos ámbitos o caminos -formal e informal- como «lugar de justificación»y «lugar de descubrimiento», respectivamente ${ }^{27}$. Parece ser que a los planos formal e informal (siguiendo a Habermas) habría que sumar un tercer ámbito virtual, en tanto lugar de realización (siguiendo a Cortina).

Segundo, muy ligado con lo anterior, dada la relevancia de la formación de la opinión y la voluntad para la democracia, el espacio público se transforma en una fuente de legitimidad del poder político. Esto último será una de las preocupaciones cruciales para Habermas, quien ya en la década de los setenta comienza a fraguar una noción robusta de legitimidad que es parte constitutiva de su política deliberativa, en virtud de lo cual sostenía que: «Legitimidad

26 Paulina Morales, «Hacia intervenciones sociales democratizantes: aportes desde el prisma discursivo de Jürgen Habermas», 11.

27 Cf. Adela Cortina, Ciudadanos del mundo. Hacia una teoría de la ciudadanía (Madrid: Alianza 1999); Adela Cortina, La Escuela de Fráncfort: crítica y utopía (Madrid: Síntesis, 2008). 
significa el hecho del merecimiento del reconocimiento por parte de un orden político. Lo que con esta definición se destaca es que la legitimidad constituye una pretensión de validez discutible de cuyo reconocimiento (cuanto menos) fáctico depende (también) la estabilidad de un orden de dominación ${ }^{28}$. Al respecto, cabe preguntarse si es que la esfera de lo virtual puede ser también generadora de legitimidad. No hay respuestas concluyentes al respecto, pero es interesante analizar ejemplos en los cuales las redes de información y comunicación virtuales han permitido poner en jaque e incluso derrotar gobiernos que han perdido legitimidad frente a sus ciudadanos. Otro caso es el de la publicidad, en donde grandes marcas internacionales han debido retirar campañas ante el rechazo masivo en redes sociales, de parte de millones de ciudadanos anónimos, ya sea porque las han considerado discriminadoras, agresivas o atentatorias contra la diversidad humana, entre otros.

Tercero, con Habermas es posible situar al espacio público como lugar de visibilización de injusticias que afectan en las sociedades modernas a los menos aventajados, y que interpelan a la democracia y a los derechos humanos en términos de sus posibilidades de acción, no solo para dar cuenta de las realidades de injusticia y para brindar caminos de abordaje, sino, previo a ello, respecto de su voluntad genuina de rescatar y mostrar dichas realidades, para otorgarles voz y rostro en el espacio público. En tal dirección, una democracia en sentido habermasiano se encuentra comprometida con la denuncia de ese tipo de experiencias, lo que significa entre otros aspectos abrir espacios de acción a la ciudadanía. Asimismo, los derechos humanos deben ser capaces de recoger en su seno la inspiración de ser defensores de la dignidad humana y no solo de garantes de un concepto negativo de libertad como no injerencia. Claramente, en este caso, las plataformas virtuales de comunicación e información tienen un potencial inmenso en términos de la visibilización de realidades excluyentes e injustas siendo una de sus principales 
fortalezas la rapidez -prácticamente instantaneidad-con que pueden difundirse, sumado a la masividad en cuanto a millones de potenciales destinatarios.

Cuarto, de relevancia es también el debate en torno a las posibilidades de un espacio público mundial, habida cuenta de la abundancia de reflexiones del autor-especialmente en las últimas dos décadas-sobre un escenario postnacional en el cual las discusiones sobre democracia y derechos humanos pueden cobrar un nuevo impulso, asumiendo que su concreción desborda las posibilidades de acción de los Estados nacionales. Con Habermas aflora nuevamente la preocupación por la legitimidad de las decisiones, ahora más allá de las fronteras de los Estados nacionales; en un espacio trasnacional o supranacional será necesario entonces cautelar ciertas condiciones propias de los procesos deliberativos, para lo cual el contar con un marco de derechos garante se torna gravitante. Es en este escenario mundial en donde cabe la pregunta por los derechos humanos de corte discursivo, en consonancia con el cariz procedimentalista de la mirada habermasiana. Los espacios de deliberación e inclusión deben ser cautelados, y para ello el modelo que propone el autor es el de una «sociedad mundial constituida políticamente». Una asociación tal requerirá de una constitución cuyo objetivo sea la conformación de una «comunidad de ciudadanos del mundo», puesto que son estos el primer sujeto constituyente de dicha sociedad. Sin embargo, como el propio Habermas ha reconocido recientemente, están aún en jaque las posibilidades de conformación de un espacio público mundial en que se exprese una verdadera transnacionalización de la soberanía popular, como reclaman los comunitaristas, dado que la vinculación de los ciudadanos en el marco de circuitos comunicativos de dicho espacio en un nivel mundial no dependería ya de los contextos de una cultura política común ${ }^{29}$. La solidaridad ciudadana que debe expresarse en el abordaje de temas y problemáticas compartidas daría de cierta forma un «salto al vacío» ante el paso a un formato 
mundial. ¿Cuál es la salida posible a esta situación? Es en parte lo que pretende abordar esta investigación por medio del concepto de «derechos discursivos» más allá de los márgenes nacionales.

Ligado a este último punto, surge entonces la pregunta por un espacio público virtual, necesariamente trasnacional, -quizás otro «salto al vacío»- en donde resulta interesante advertir las posibilidades que ofrecen las denominadas «comunidades virtuales». Dichas comunidades tienen entre sus condiciones o rasgos propios los siguientes: i) Se organizan por medio de sistemas telemáticos de comunicación; ii) Sus miembros pueden estar unidos por intereses diversos, confluyentes eso sí en la naturaleza de la comunidad a la que se adscriben virtualmente; iii) En sus comunicaciones están «fuera de ahí», pero no obstante «ahí», no hay un lugar físico en que esas interacciones se producen, pero ciertamente hay un lugar virtual; iv) Responden a una cultura de cierta forma nómada, porque sus miembros pueden moverse fácilmente, entrar y salir de ellas y, sin embargo, no pertenecer en el sentido físico del término, como un estar ahí corporalmente; lo que aquí opera es una desterritorialización; v) Frente a esta desterritorialización, actúa la sincronización y la interconexión ${ }^{30}$. Como acertadamente se grafica, «la multiplicación contemporánea de los espacios hace de nosotros un nuevo tipo de nómadas: en lugar de seguir líneas errantes y migratorias dentro de una extensión dada, saltamos de una red a otra, de un sistema de proximidad al siguiente. Los espacios se metamorfosean y bifurcan bajo nuestros pies, forzándonos a la heterogeneidad» ${ }^{31}$.

Esto último tiene diversas implicancias para una lectura desde los derechos humanos. Las dificultades para situar en ellas este concepto, inclusive, no son pocas. ¿Cómo se despliega la responsabilidad

30 Un aporte indispensable a este respecto lo constituye el libro Comunidades en el ciberespacio, en donde se advierte desde el inicio: "La comunidad se conceptualiza ahora no en relación con la proximidad física, sino en relación con las redes sociales. Los teléfonos, los coches y los aviones hace ya tiempo que demostraron que era posible establecer y sostener importantes relaciones sociales fuera de nuestra vecindad física inmediata». Marc Smith y Peter Kollock, Comunidades en el ciberespacio (Barcelona: Uoc, 2003), 39.

31 Pierre Lévy, ¿̇Qué es lo virtual? (Barcelona: Paidós, 1999), 23. 
en este marco? ¿Cómo transitar hacia un concepto de ciudadanía $\operatorname{digital}^{32}$, por ejemplo, cuando las personas saltan de un sitio a otros en las redes virtuales? Cierto es que la caracterización anterior remitía al concepto de comunidades virtuales, mas es difícil establecer los límites de estas, como también dilucidar el sentido de pertenencia de sus miembros, por ejemplo.

\section{La perspectiva del ciberhumanismo}

\subsection{La sociedad tecnológica de hoy}

Ciertamente, el escenario del ciberespacio es actualmente uno de los preeminentes en donde se juegan nuevas formas de expresión e interacción humanas. Y su existencia misma es fruto del desarrollo tecnocientífico imparable que ha permitido la generación de una esfera virtual de alcances quizás aún insospechados y dimensiones inconmensurables ${ }^{33}$.

Desde una perspectiva filosófica, las implicancias del desarrollo tecnológico son numerosas, entre ellas, en referencia a las posibilidades que el nuevo escenario plantea para los hombres de hoy, frente a interrogantes como quiénes somos, quienes queremos

32 Algunos autores se refieren a la ciudadanía digital como una forma de «hiperciudadanía», en el sentido de una forma de ejercicio de la participación política de mayor profundidad, la cual «supone un ejercicio más pleno de los derechos ya consolidados, así como la promoción de nuevos derechos». Esta hiperciudadanía sería consecuencia de una sostenida implantación de los derechos de cuarta generación, entre los cuales identifica: la apropiación social de la tecnología, el derecho a participar de una gobernanza electrónica, la promoción de políticas de inclusión digital, la defensa del software libre, entre otros. "Los derechos humanos de cuarta generación y sus implicaciones en la sociedad contemporánea», 5.

33 En tal sentido, resulta interesante advertir también la emergencia de un conjunto de reflexiones sobre las implicancias políticas -vinculadas al ejercicio del poder- en relación con las nuevas tecnologías. Un ejemplo destacado a este respecto lo constituye el ya famoso escrito de Langdon Winner titulado «i̇Tienen política los artefactos?», contenido en su libro La ballena y el reactor. Una búsqueda de los límites en la era de la alta tecnología, en donde señala: «No existe idea más provocativa en las controversias acerca de la tecnología y la sociedad que la noción de que los objetos técnicos poseen cualidades políticas. Está en discusión la afirmación de que las máquinas, las estructuras y los sistemas de la cultura material moderna pueden ser juzgados adecuadamente no solo por su contribución a la eficiencia y productividad y por sus efectos secundarios ambientales positivos y negativos, sino también por la manera en que pueden encarnar formas específicas de poder y autoridad». Langdon Winner, La ballena y el reactor. Una búsqueda de los límites en la era de la alta tecnología (Barcelona: Gedisa, 2008), 25. 
ser o, gracias a las nuevas tecnologías, quiénes podemos ser. Como se observa, se trata de preguntas trascendentes cuyas respuestas no están ni cuanto menos claras, ni pueden ser establecidas de antemano ni son de fácil abordaje.

En dicho marco, la reflexión sobre derechos humanos aflora llena de sentido y de necesidad. En relación con los tópicos de este artículo en particular -la emergencia de un campo de derechos humanos en el ciberespacio-, ya algunos autores han realizado sus aportes y han reflexionado sobre cómo surge todo un conjunto de prerrogativas cuya seña de identidad es el entorno en el cual se despliegan estas: el de las redes y tecnologías de la información y la comunicación, dentro de lo cual el espacio Red Internet cobra una centralidad indudable. Se trata de una tecnología se ha transformado en una verdadera «revolución social y cultural cuyas consecuencias aún hoy difícilmente podemos pronosticar ${ }^{34}$. Esto porque, de la misma forma que Internet puede ser vista como la estructura social más democrática y participativa que existe en la actualidad, en tanto posibilita que el derecho a la libertad de expresión se amplíe y extienda, también permite que se utilice indebidamente para fines fraudulentos. No sin razón, entonces, se remite al ciberespacio -el hogar que alberga a Internetcomo «esa turbulenta zona de tránsito de signos vectorizados», o metafóricamente, un «ordenador de Babel» ${ }^{35}$.

De esta forma, la reflexión ética y política sobre el nuevo escenario tecnológico, especialmente vinculada a la pregunta por los derechos humanos, es fecunda en términos de la necesidad permanente de pensar lo humano. Con esto, de paso, resulta posible hacer frente a uno de los flancos de crítica más frecuentes en torno al desarrollo tecnocientífico, a saber, su consideración como un campo exento de contenido normativo y, más aún guiado por una racionalidad instrumental como sello de identidad. «Se suele acusar a la tecnología

34 Íñigo Galzacorta, Iñaki Ceberio y Javier Aguirre, Diseñando el futuro. Reflexiones desde la filosofía (Madrid: Plaza y Valdés, 2011), 13.

35 Pierre Lévy, ¿Qué es lo virtual?, 45 
de los males del mundo moderno», se queja Cardwell en su Historia de la tecnología ${ }^{36}$.

En efecto, la referencia a la necesidad de delimitar fronteras para la actividad tecnocientífica aparece de manera recurrente en la literatura sobre el tema, en virtud de la consideración de dicho campo como autonomizado en su funcionamiento o librado a la suerte de una "racionalidad "meta-ética" y "meta-política", en cuanto que investiga, opera, manipula y produce prescindiendo de consecuencias -para la naturaleza, el hombre, la sociedad $-\gg^{37}$. Pero, entonces, ¿̇es que acaso la pervivencia y protección de los derechos humanos es incompatible con el desarrollo tecnocientífico, dada su racionalidad instrumental inherente? No se trata de oponer como campos excluyentes tecnología y derechos humanos. Empero, tampoco se trata de un relativismo exacerbado donde todo vale. Y menos aún de aplicar una lógica consecuencialista, esto es, una valoración de ciertos desarrollos científicos y tecnológicos dependiendo de sus resultados, en lo que sería una especie de evaluación a posteriori de marcado cariz utilitarista. Parece ser que lo posible se encamina por la vía del establecimiento, desde lo ético y lo político, de condicionantes o límites previos, en una suerte de demarcación del terreno de acción de la ciencia y la tecnología. Frente a esto, los derechos humanos aparecen como el límite o frontera que no debiese ser traspasada, ni en la fase de investigación ni en la posterior fase de aplicación y extensión de los avances tecnocientíficos.

Ciertamente, el espacio en que actualmente se despliegan y profundizan -y en algunos casos lamentablemente retroceden- los derechos humanos, está cambiando aceleradamente. El contexto de 1948, cuando nace la Declaración Universal de Naciones Unidas, ya no es el mismo. Extensos e intensos cambios han ocurrido en estos

36 Donald Cardwell, Historia de la tecnología (Madrid: Alianza, 1996), 489.

37 Manuel Maceiras, «Tecnociencia y política de derechos humanos», en Derechos Humanos: la condición humana en la sociedad tecnológica, 104. 
casi setenta años de existencia de este documento canónico. Como bien reconocía Bustamante en 1999:

Los problemas ético-jurídicos relacionados con dichos derechos [los del 48], que están pidiendo urgente respuesta, no están por ser respondidos, sino más bien por ser reformulados. Leer entre líneas en la tecnología telemática nos permite descubrir nuevas estructuras sociales en período de incubación, nuevas formas de relación y de intercambio amplificadas y aceleradas por mor del avance tecnológico ${ }^{38}$.

La necesidad de establecer regulaciones en el ciberespacio, o a los cibernautas que en él coexisten, es una realidad innegable, aunque quizás opuesta al sentido originario de un espacio virtual en que todo era posible. En 1999, Lláser advertía al respecto: «En el mundo real rigen pautas y reglas que se remontan a los albores de la civilización humana. Pero Internet no es una realidad en busca de normas ${ }^{39}$. Sin embargo, casi dos décadas después, resulta imposible adherir a dicho aserto.

$\mathrm{Al}$ respecto el caso de la libertad de expresión es clara. A juicio de diversos autores, tal libertad se compone de tres elementos básicos: la libertad ideológica, la libertad y el derecho a recibir información veraz, y la libertad de expresar la propia opinión. Tales elementos, a su vez, se constituyen como derechos en sí mismos en muchos de los ordenamientos jurídicos actuales. En el concierto de Internet, es claro cómo lo relativo a la veracidad de la información se puede ver fuertemente afectada por la difusión de contenidos erróneos o derechamente falsos (fake news) que son subidos a la red justamente con la intención de confundir y desinformar. En el caso de la libertad para expresar la propia opinión, el ciberespacio aparece a simple vista como un paraíso para ello, mas no se puede desconocer -la

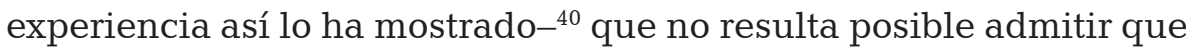

38 Javier Bustamante, «Derechos humanos en el ciberespacio», en Derechos Humanos: La condición humana en la sociedad tecnológica, 164.

39 Pilar Llácer, «Internet y derechos humanos: la libertad de expresión en el ciberespacio», en Derechos Humanos: La condición humana en la sociedad tecnológica, 186

40 No se puede desconocer la fuerte presencia de contenidos nocivos en la red, ya sea por sus altos niveles de violencia, por su naturaleza sexual o por responder a conductas consideradas delictivas: pedofilia, pornografía con menores, tráfico de órganos, etc. 
cualquier opinión pueda tener cabida, sin una mínima discriminación respecto de sus contenidos. La emisión de opiniones en el espacio virtual también requiere de límites que se basan justamente en proteger la libertad de los demás, la dignidad propia de cada ser humano y la necesidad de una convivencia pacífica aún -o más aún- en un entorno ciberespacial.

Frente a las visiones catastrofistas en torno a la tecnología, una posibilidad de lectura diferente es asumir que esta «no puede ser vista como algo deshumanizador. No es ella quien excluye, sino las personas. Un uso humano e inteligente de la tecnología tiene que hacer de la Tierra un mundo en el que todos podamos volar» ${ }^{41}$. Con esto, de paso, se restituye la responsabilidad de los seres humanos sobre el particular, contrariamente a la idea de una técnica librada a su propio arbitrio, desde una lógica exonerante que difumina las responsabilidades tanto de quienes desarrollan nuevas tecnologías como de quienes las utilizan y se desenvuelven en ellas.

\subsection{El ciberhumanismo como una ética para el habitante de la sociedad tecnológica}

Cierto es que, como se ha mostrado en estas líneas, la reflexión sobre lo humano es uno de los leit motiv que guían la reflexión sobre derechos humanos de cuarta generación. Y no pocas obras aluden a ello por medio de denominaciones como «condición humana» en la era tecnológica, «condición posthumana»o «condición transhumana», entre otras. Las certezas que en su momento brindó el humanismo han sido cuestionadas en el escenario de la sociedad tecnológica, pues como bien se reconoce, «en la actualidad no tenemos nada claro ni cuál sea la naturaleza legítimamente humana, ni cuáles sus fines. Si en algo vacilamos en nuestra llamada cultura humanística, es en el modelo de humanismo para nuestro tiempo» ${ }^{42}$.

\footnotetext{
41 Javier Bustamante, «¿̇Qué puede esperar la democracia de internet? Una reflexión sobre la crítica de Langdon Winner al poder político transformador de la tecnología», 48.

42 Manuel Maceiras «Tecnociencia y política de derechos humanos», 103
} 
A interrogantes como aquellas ha intentado responder Graciano González ${ }^{43}$ en una de sus últimas obras, en donde propone el término «ciberhumanismo» como acervo o contenedor de la reflexión ética en la actualidad, en la forma de una posible pauta de realización y de sentido para los habitantes de la sociedad tecnológica de hoy. Cierto es que tradicionalmente la tecnología ha sido vista como el terreno de la racionalidad instrumental, mas la propuesta de este autor parte de una constatación basal al respecto: «hoy no es posible proponer y plantear una alternativa de significado y sentido a las actividades humanas, y de nosotros mismos, si no es en este cruce de caminos entre tecnología y ética ${ }^{44}$. Es esta intersección la que requiere, a juicio del autor, de un ciberhumanismo -o ciberhumanismus, como prefiere llamarle para preservar el matiz latino del término- que se despliegue al menos en tres niveles: i) En el de la subjetividad de los proyectos personales individuales; ii) En la intersubjetividad de los proyectos con otros; iii) En la globalidad de proyectos que responden a una manifiesta "vocación universal» congruente con la sociedad tecnológica en la que se constituyen como tales.

Mas en virtud de lo que se ha expuesto anteriormente, sobre el nuevo escenario de una sociedad tecnológica, es indudable que la dimensión ética en este marco puede resultar compleja, en parte debido a lo que se señalaba en torno a la primacía de una razón instrumental asociada al campo de la tecnología y la técnica. A juicio de González, lo que se produce es una situación dilemática, entre dos polos que en ninguno de los casos resultan satisfactorios. Por un lado, la tecnología podría ser vista como un «producto espurio», en tanto produciría bienes sin necesidad de legitimación. Por otro, la ética actuaría al modo de un aditamento o añadido en el proceso de producción de bienes y servicios. Sin embargo, en cualquiera de los dos casos, la ética termina teniendo un papel accesorio. Pero entonces,

43 Filósofo español, académico de la Facultad de Filosofía y Ciencias de la Educación de la Universidad Complutense de Madrid.

44 Graciano González, Ciberhumanismus. Una ética para el habitante de la sociedad tecnológica (Sevilla: Doss, 2010), 13. 
¿̇cuál es la salida a tal disyuntiva? Pasar de una situación dilemática a una «situación conjuntiva», entendida esta como una situación tensional que permita trascender a esta polarización que implique escoger entre ética o tecnología. Esto, proponiendo «lugares de paso entre la una -como humanismo- y la otra -descrita como sociedad tecnológica- $[\ldots]$ para que ninguna de las dos perspectivas quede reducida la una a la otra, ni menos aún, queden "'superadas"»45.

Teniendo en cuenta lo anterior, González visualizará al humanismo, en este contexto, como una posibilidad de discurso ético sobre las consecuencias o los riesgos de la tecnología en la sociedad actual, pero no en términos de un acercamiento meramente epistemológico para el conocimiento de los nuevos avances tecnocientíficos, sino en términos de la racionalidad que está en juego. No se trata solo de una «razón ordenadora» sino también de una «razón de sentido», como partes o dimensiones consustanciales de la racionalidad moderna, en donde lo ético y lo político tienen un papel insustituible. No obstante, si el objetivo de la racionalidad es orientar la acción, en ello compite ahora con la tecnología, que indudablemente va también modelando las formas de vida, desde su introducción en los espacios más cotidianos hasta los más globales.

Frente ello, el autor se pregunta acerca de las posibilidades de sostener un ciberhumanismo, «en la medida en la que recoge, junto a la pregunta por el sentido de lo humano, el referente cultural de la cibercultura y la tensión de la innovación como campo explícito de una posible, por deseable, interrelación entre tecnología y ética ${ }^{46}$. El nuevo escenario que representa la sociedad tecnológica es el terreno en donde habita el hombre de hoy, y esto supone una condición que no puede ser omitida por la reflexión filosófica actual, dado que en él es donde los seres humanos tienen que desplegarse, pensarse y decirse. Y la sociedad tecnológica es donde deben cumplirse, entonces, estas tareas de autocomprensión, reflexión y expresión, en

45 Graciano González, Ciberhumanismus, 29.

46 Graciano González, Ciberhumanismus, 139. 
relación consigo mismo y con los otros, en un entramado cultural que se ve también profundamente imbricado con el desarrollo tecnológico.

A ello responde la noción de «cibercultura» que acuña este autor, entendiendo que hablar de ciberespacio necesariamente implica la existencia de un correlato cultural en relación con un nuevo espacio de despliegue humano en el mundo. Su definición de cibercultura deberá ser entendida como una "visión general» que trasciende al fenómeno técnico mismo en el mundo de las telecomunicaciones, para introducirse también en el mundo de los valores dadores de sentido y de legitimación. ¿̇Por qué es necesario hablar de la dimensión cultural de la tecnología? En una evidente referencia de cariz habermasiano, porque «la colonización de nuestros mundos de la vida por la tecnología, es lo que nos permite hablar de dimensión cultural de la misma y, a renglón seguido, poner entre paréntesis una visión puramente determinista; como si la tecnología tuviera solo un carácter meramente instrumental -que, sin duda, lo tiene- pero que es algo más» ${ }^{47}$.

Así, el ciberhumanismo emerge como un referente del imaginario que representa el humanismo, pero ahora en una especie de relectura en un mundo altamente tecnologizado, en donde igualmente es posible pesquisar las huellas de humanidad a través de los rastros de la vida humana compartida con otros. Siendo el humanismo una metáfora, no es a juicio de González una metáfora baldía ni rasa, pues opera desde ese espacio de interacciones $-\mathrm{y}$ sus consiguientes significantes- entre seres humanos, que viene de mucho antes del advenimiento de la tecnología a nuestras vidas.

De esta forma, como bien precisa el autor, tiene sentido seguir hablando de humanismo. Y de ciberhumanismo, en este caso. Más allá de consideraciones fatalistas sobre el humanismo y sus posibilidades de pervivencia en la actualidad, el propio discurso que propugna su superación (posthumanistas) no impide en ningún caso la pregunta por la condición humana, por la humanidad o por el 
sentido de esta, aunque -como bien se matiza- «tampoco nos autoriza a hablar de significatividad de lo humano de cualquier manera, ni a cualquier precio» ${ }^{48}$. Asumir esa condición tensional en que ética y tecnología se encuentran, refuerza la necesidad -traducida en clave de capacidad-, por parte del ser humano, para plantearse preguntas gravitantes como estas: quiénes somos, quiénes queremos ser. Parece ser que esta última interpelación es una de las más cruciales en el nuevo escenario de una sociedad tecnológica, dado que sus posibles respuestas se amplían cada vez más conforme surgen nuevos avances tecnocientíficos, desde la adición de una consideración inexorable: quiénes podemos llegar a ser. Los debates en torno al transhumanismo y al posthumanismo así lo reflejan, aunque sea imposible abordarlos en estas líneas ${ }^{49}$. Pero sí desde la propuesta de un ciberhumanismo, como aquí se propone.

La pregunta por el sentido de la existencia es eminentemente ética y se despliega en diversas facetas, incluyendo el sentido de la vida, del mundo, de la historia y, cómo no, el sentido de la tecnología. Es -como precisa González- una interrogante ética, pero indisolublemente unida a la dimensión del desarrollo tecnológico como correlato de posibilidades para arribar a respuestas. Es más, no se trata de una relación de externalidad o concomitancia entre ética y tecnología, sino de profunda imbricación que ha llegado a modificar el espacio en que el ser humano es y está en el mundo. El ciberespacio, en tanto campo virtual, se ha vuelto una esfera en la cual se está de manera inexorable en el mundo de hoy. La amplísima extensión de las redes de comunicación e información han llegado incluso a tareas y acciones más cotidianas, como comunicarse por teléfonos móviles, videoconferencias, correos electrónicos, comerciar on line, etc. Así las cosas, el hombre se halla habitando esta sociedad

48 Graciano González, Ciberhumanismus, 175.

49 Pero hágase referencia como indispensable a esta consideración al respecto: «Vemos así confirmado el diagnóstico del posthumanismo, cuando sostiene una búsqueda de la causa del hombre en la inquietud que genera su insoportable pérdida. Y, a la vez, asistimos perplejos a su propia superación, cuando la memoria, corriendo el riesgo de quedar colonizada por la tecnología, se yergue para reclamar un lugar al sol de una realización con sentido». Graciano González, Ciberhumanismus, 179. 
tecnológica, global, virtual, en donde no solo puede reconocer la realidad de un mundo transversal, «sino también la virtualidad de un mundo en común con otros, a fuer de compartido, por inevitablemente compartible ${ }^{50}$. Por tanto, la pregunta en torno a quiénes queremos y podemos ser indefectiblemente contiene en su respuesta referencias a con quiénes estamos conectados.

\subsection{Puntos de convergencia entre el prisma discursivo habermasiano y el ciberhumanismo}

Como se señaló líneas arriba, González afirma que tiene sentido seguir planteando la pregunta por lo humano en la actualidad, más aún habida cuenta del nuevo escenario que representa la sociedad tecnológica. Desde este reconocimiento, su propuesta de un ciberhumanismo implica claramente una defensa del humanismo releído ahora con base en nuevas coordenadas como las explicitadas hasta el momento.

En dicha senda, es posible advertir algunos puntos de confluencia con el prisma discursivo habermasiano. En primer término, ambos autores recurren a un enfoque hermenéutico, tanto en el caso de la comunicación como en el de un humanismo en el ciberespacio. Como se sabe, Habermas desde sus orígenes visualizó la emergencia de procesos comunicativos en los cuales lo que se genera es una relación sujeto-sujeto facilitada por medio del lenguaje. Y es precisamente esta relación entre sujetos la que remite a una perspectiva tanto ética como hermenéutica del fenómeno de la comunicación entre los seres humanos. Es hermenéutica porque se requiere un entendimiento mínimo entre hablante y oyente, pues de otra forma no puede existir acción comunicativa lograda. Es ética porque dichas acciones no podrían logran éxito sin un reconocimiento recíproco entre los interlocutores en tanto interlocutores válidos dotados de capacidad comunicativa. El cariz hermenéutico está dado también

50 Graciano González, Ciberhumanismus, 181. 
porque se trata de sujetos que indefectiblemente están en el mundo interpretándolo a partir de sus propios acervos vitales.

Desde la óptica del ciberhumanismo, González apuntará a una idea similar a esta última, es decir, a la capacidad interpretativa que tiene todo ser humano, al punto de llegar a hablar de un «humanismo hermenéutico», que, en el nuevo escenario de las tecnologías, se transforma en un recurso metodológico para reinterpretar(se). Así, «en un mundo dado para ser interpretado, -y las posibilidades de la tecnología para abrir nuevas interpretaciones son determinantes-, la hermenéutica alcanza una hegemonía ineludible» ${ }^{51}$.

Un segundo aspecto convergente está dado por la centralidad de la noción de responsabilidad histórica en el pensamiento habermasiano, la cual puede ser leída -desde la perspectiva ciberhumanista- en virtud del énfasis en el papel de la memoria en torno a lo humano. En cuanto a lo primero, como se conoce, el tópico de la historia, y en particular de la responsabilidad histórica, ha estado presente en la reflexión del autor germano al modo de un trasfondo de sus reflexiones principales sobre democracia y derechos. Sus raíces se encuentran en los tempranos desarrollos que junto a Karl-Otto Apel dieran vida a lo que hoy se conoce como ética comunicativa, dialógica o del discurso, a inicios de los años setenta del pasado siglo.

Pese a las divergencias que con los años fue estableciendo Habermas con Apel, las referencias a la memoria y a la responsabilidad histórica nunca dejarán de estar presentes en su pensamiento. Así, retomará esta preocupación al calor de sus reflexiones sobre las identidades nacionales y postnacionales, y se mantendrá en obras siguientes. En todas ellas, se pregunta por la posición de Alemania en el convulsionado escenario de fines de los ochenta, pero no solo en relación con cuestiones contingentes de entonces, como la caída del muro, sino anteriormente en referencia al nazismo como una herida aún presente en el devenir alemán y mundial. Auschwitz representará 
una vergüenza para la humanidad entera, una verdadera catástrofe moral frente a la cual tiene sentido preguntarse si es que acaso «ino funda ese carácter fortuito del mero habernos librado de aquello una responsabilidad intersubjetiva, una responsabilidad en lo tocante a los plexos de vida distorsionados $[\ldots]$ ? $\rangle^{52}$.

Interrogantes como aquella dirigirán la mirada necesariamente a la forma en que se prosiguen las tradiciones histórico-culturales, bajo una nueva pregunta interpeladora, a saber, si es posible aprender de la historia, sustentada en la crítica del autor al historicismo, en tanto cómplice de una historia «encerrada en un museo» que propiciaba la pasividad de los sujetos del presente. Por el contrario, lo que se requiere es una hermenéutica de la historia que reconoce que aprendemos de nuestras tradiciones en diálogos con textos y autores que de esta forma siguen apareciendo como contemporáneos. En este marco, los procesos de aprendizaje de la historia emergen «por experiencias que se nos imponen, es decir, por problemas que nos sobreviven de improviso y en los que fracasamos a menudo de forma bien dolorosa y con muy importantes consecuencias [...] la cuestión es si podemos aprender de aquellos acontecimientos en los que se refleja el fracaso de las tradiciones» ${ }^{53}$.

Toda esta reflexión sobre la responsabilidad histórica se renueva y nutre cuando se la traslada al plano de un espacio trasnacional virtual en el cual los derechos humanos se ven indefectiblemente interpelados, tanto en sus posibilidades de concreción como en términos de posibles amenazas hacia ellos. En este marco, cuestiones como la autonomía pública y privada, la dignidad, libertad de expresión o la necesidad de cautelar la memoria como resguardo a la prevalencia de los derechos humanos para las generaciones futuras, se vuelven materia de relectura, ahora en un contexto fuertemente tecnologizado que ha generado nuevas formas y plataformas de comunicación. A este ejercicio de reflexión y revisitación debe

52 Jürgen Habermas, Más allá del Estado nacional (México: Fondo de Cultura Económica, 1998), 88.

53 Jürgen Habermas, Más allá del Estado nacional, 48. 
sumarse indudablemente la filosofía, pues «solo de esta manera habrá una posibilidad de proteger los derechos humanos básicos y de fomento de la responsabilidad en la era digital $»^{54}$.

Desde la mirada del ciberhumanismo la referencia a la memoria aflora como una necesidad frente a la posible deshumanización que pueda significar el desarrollo tecnocientífico. Tal deshumanización puede expresarse en diversos campos: las interacciones virtuales entre cibernautas, nuevos espacios de trabajo virtual, los intercambios económicos, las intervenciones eugenésicas, entre otros. Frente a esto, la memoria permitiría rastrear las «huellas» de humanidad en el mundo «vertebrado» en torno al querer ser que se ha ido concretando en el tiempo, en buena medida delineado por los avances de la tecnología. En virtud de esto, el trabajo hermenéutico de interpretar el mundo e interpretarse a sí mismo no parte nunca de un punto cero o tabula rasa, sino que se encuentra mediado por los contenidos de la memoria. Como bien se precisa, «la pregunta que tendríamos que contestar es si este nuevo espacio-ciberespacio- [...] puede dejar de lado las "huellas de humanidad" tan afanosamente perseguidas por las mujeres y los hombres de todo tiempo y condición $»^{55}$.

Finalmente, un tercer punto de coincidencia entre el prisma discursivo y el ciberhumanismo está dado por la propuesta de González en torno a ciertas condiciones del discurso para poder resituar el tema del humanismo ahora en el nuevo contexto ciberespacial. Con Habermas, como se aludía anteriormente, se configura una situación tanto real como ideal del habla en donde deben cumplirse ciertas presuposiciones de la comunicación ideales y universalmente válidas, entre ellas: a) La corresponsabilidad, tanto propia como de los participantes en el discurso, al entrar en él; b) La igualdad de derechos de todos los participantes, considerados interlocutores válidos para estar allí discutiendo en condiciones de simetría, sin coerción de ningún tipo y en donde la calidad de

54 Robin Mansell, «Introduction. Human rights and equity in Cyberspace», 6.

55 Graciano González, Ciberhumanismus, 180. 
los argumentos sea lo que prime; c) El objetivo discursivo de la susceptibilidad de consenso (universal) de todas las soluciones a los problemas que presenta la vida en comunidad, dentro de lo cual caben los problemas de fundamentación de normas.

Frente a ello, desde el ciberhumanismo de González se plantea la existencia de un conjunto de condiciones de posibilidad para hablar de humanismo y «mantener» dicha conversación, con miras al abordaje del conflicto ético que emerge entre querer ser y poder ser, pues como bien se reconoce, «ni poder ni deber/querer son nada, en términos filosóficos, mientras no se abran al discurso. "Abrirse al discurso" tiene una consideración curiosa; porque entonces estamos diciendo que el discurso es ya lo abierto por excelencia, puesto que siempre estará a expensas de "nuevos" haceres que requerirán "nuevos" decires o discursos» ${ }^{56}$. En esta reflexión, como será posible advertir, irán aflorando algunas coincidencias o proximidades con el prisma habermasiano, y en algunos casos posibilidades de complementación frente a ciertas limitaciones de dicho enfoque. Tales condiciones se traducirán en los puntos que siguen.

a. La recuperación de un modelo tensional

La primera referencia a este respecto dice relación con la diferenciación frente al mundo de la filosofía anglosajona, pues para González la reflexión sobre este humanismo «de nuevo cuño» es propia de la filosofía continental. No implica ello, como bien lo precisa, una consideración del pragmatismo como un antihumanismo, sino la necesidad de distinguir «dos visiones» de la realidad. Más aún, desde lo político es claro cómo el modelo pragmatista se ha ido asentando en diversos campos del devenir humano, ya sea en torno a estilos de vida, modelos de empresas, de sanidad, de producción artística, entre otros. Frente a esto, la propuesta del autor es reflexionar sobre estas formas de vida anejas a comprensiones filosóficas distintas por medio de un ejercicio de delimitación teórico-conceptual inicial. 
Como claramente señala, «lo que pretendemos identificar, pues, en esta primera aseveración, es el "lugar" de la pregunta; cuestión no desdeñable, si pretendemos hablar de ciberhumanismo» ${ }^{57}$. Si se tuviese que ubicar a Habermas en estas perspectivas, claramente se lo encuentra del lado de la filosofía continental.

b. El carácter holista

A juicio de González, el cariz holista resulta inherente a una perspectiva como el ciberhumanismo, en términos de dilucidar unos rasgos generales y compartidos de lo humano, en torno a cuestiones como el logro de la felicidad, de una vida buena, de la justicia, del respeto, del bienestar, entre otros. Cierto es que se trata de cuestiones absolutamente debatibles y, más aún, imposibles de ser consensuadas en cuanto a su contenido; por ello es que se reconoce que su carácter indefectiblemente «formalista» del enfoque holista puede ser blanco de crítica. Mas no se trata solo de la configuración de un punto de vista o visión general sobre lo humano, sino de una «alternativa práctica de liberación personal y comunitaria; como expresión de la capacidad significativa del "querer ser" $"{ }^{58}$, en tanto puedan transformarse en criterios para orientar la acción con un sentido moral humano y humanizador, trascendiendo así a un mero activismo.

Desde la mirada habermasiana, su propuesta discursiva asume también este carácter formal, más aún, procedimental, entendiendo que sobre cuestiones de vida buena se puede debatir, pero no necesariamente llegar a consensos, como sí se vuelve indispensable en materia de normas, entendidas como «mínimos de justicia», en palabras de Cortina ${ }^{59}$. Con Habermas y más allá de él, la orientación y necesidad de consenso se vuelve todavía más patente en el contexto tecnologizado en que se desenvuelven las interacciones humanas en la actualidad. Dicho consenso posible puede dirigirse a diversos

57 Graciano González, Ciberhumanismus, 202.

58 Graciano González, Ciberhumanismus, 203.

59 Cf. Adela Cortina, Ciudadanos del mundo. Hacia una teoría de la ciudadanía (Madrid: Alianza, 1999). Adela Cortina, Ética sin moral (Madrid: Tecnos, 2000). 
ámbitos en relación con esto, pero son dos los aspectos que se destacan en la literatura sobre el tema. Por una parte, en torno a la libertad de expresión, su relectura en la esfera ciberespacial, sus posibilidades de concreción y limitaciones. Por otra, la necesidad de extender la Internet y el acceso a la informática a la mayor parte de usuarios posibles; en este último caso, se habla incluso de una nueva prerrogativa al respecto.

c. El «uso práctico» del carácter holista

Si en el punto anterior se remitía al establecimiento de ciertos criterios sobre lo humano, ellos se transforman en definitiva en un discurso moral que cumple labores de «control»y «verificación» respecto de los discursos y de las prácticas sobre la condición humana, siendo dicha condición lo que le otorga su sentido y legitimidad. De esta forma, "un discurso humanista, en este contexto tecnológico, asume como límite, por arriba, la afirmación de la dignidad del hombre y sus derechos; y, por abajo, descubre la posibilidad ética del consenso y, junto con él, la posibilidad de decir "no", a la vez que reivindica la exigencia de no convertir al otro en víctima» ${ }^{60}$.

Como se puede advertir, afloran resonancias habermasianas respecto de ello. Aunque el autor germano no se declare a sí mismo como un humanista, sí es clara la presencia del tema de los derechos en su ya extensísima obra. Respecto de la idea de dignidad humana, realiza incluso un mea culpa en términos de la débil atención que a su juicio ha prestado a ella en el marco de su reflexión sobre derechos, tal como expresamente lo reconoce en La constitución de Europa ${ }^{61}$. Junto con esto, la tarea de búsqueda de consenso en el marco de procesos discursivos supone claramente

60 Graciano González, Ciberhumanismus, 204.

61 Y al respecto llega a preguntarse incluso si dicha omisión tendrá consecuencias para su propuesta del «sistema de los derechos» y para su «lectura deflacionaria» del principio de discurso, puntualmente en relación con los derechos fundamentales, aunque luego de un detallado excurso concluirá que no es así en ambos casos. Toda esta discusión se encuentra recogida en el primer capítulo de $L a$ constitución de Europa titulado «El concepto de dignidad humana y la utopía realista de los derechos humanos». Jürgen Habermas, La constitución de Europa (Madrid: Trotta, 2012). 
una consideración entre sus participantes como interlocutores válidos, que están allí en tanto afectados (que no víctimas) por las normas que se discuten.

d. La superación del patrimonialismo

En un ejercicio de pluralismo y apertura, González precisa que el humanismo que propone, ahora en el marco del ciberespacio, no puede erigirse como patrimonio de nadie, como tampoco en tanto «reserva de esencias» de lo humano, como si se tratase de un acervo al cual echar mano en tiempos complejos. Esto, porque de ser así, se estaría hablando de un humanismo como algo ya hecho, concluido,

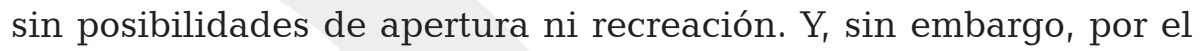
contrario, «sostenemos que lo humano es lo abierto por excelencia ${ }^{62}$.

Junto con ello, y en consonancia con la tradición discursiva, González defiende la búsqueda de consenso sobre unos «mínimos de contenido humano» institucionalizables y que actúen al modo de cánones para las actividades humanas. Este consenso debiera incluir, asimismo, referencias interculturales diversas, con miras a trascender el prisma etnocéntrico que frecuentemente se adscribe a la reflexión sobre lo humano, y de manera nítida a los planteamientos sobre derechos humanos. Con Habermas se remite a una idea de mínimos de justicia -aunque no utilice el autor esta noción explícitamenteen la forma de normas compartidas fruto del consenso logrado a través del discurso. En la esfera discursiva se desplegarán sujetos contextualizados temporal y espacialmente, por tanto también con pertenencias culturales diversas. El autor asume inclusive las críticas al enfoque de los derechos humanos como un proyecto occidental.

En tal sentido, Habermas realiza una interesante contribución en torno al necesario diálogo entre Occidente y Oriente en materia de derechos humanos, que pretende ser una respuesta a la extensión global de la modernidad social, más que una defensa del cuestionado trasfondo cultural de la civilización occidental en materia de derechos 
humanos; como se reconoce, el debate en torno a una adecuada lectura de tales prerrogativas no apunta a «lo deseable de la modern condition, sino acerca de una interpretación de los derechos humanos que haga justicia al mundo moderno también desde la perspectiva de otras culturas» ${ }^{63}$.

\section{e. La referencia al proyecto moderno}

De manera inequívoca, el discurso sobre el ciberhumanismo reconoce como punto de origen el proyecto moderno, pero no al modo de una linealidad exenta de saltos, sino en tanto trayectoria en parte «truncada», en ocasiones «rehecha», empero "por reconstruir». Las reminiscencias modernas remiten a la máxima kantiana de atreverse a pensar por sí mismo, en cuanto posibilidad liberadora para el hombre, como también a una racionalidad práctica que se legitima en virtud de los valores que la propia razón descubre, en tanto fines esenciales o razones de humanidad. No se trata, no obstante, de una visión idealizada de la modernidad; ya se ha dicho que remite a un proyecto que ha mostrado asperezas en su devenir -dirá incluso González que en algunos casos ha «producido monstruos»-. De lo que se trata es de asumir su potencial emancipador y sus posibilidades de reconstrucción y proyecciones, algo en lo que habrá coincidencia con la visión habermasiana de la modernidad como un "proyecto inacabado» y por ello vigente. En tal sentido, «la filosofía no puede dejar de ser "moderna". En su condición de límite, la modernidad es un lugar de frontera, listo para ser traspasado por la fuerza de la iniciativa de una actividad que no retrocede ante la denuncia del poder convertido en violencia y ante la exigencia de construir un espacio político post-totalitario» ${ }^{64}$.

Ligado a esto último, los derechos humanos cobran una centralidad indiscutible en el seno del pensamiento moderno, especialmente desde el siglo $\mathrm{xx}$, habida cuenta de los hechos que

63 Jürgen Habermas, La constelación posnacional (Barcelona: Paidós, 2000), 156-157.

64 Graciano González, Ciberhumanismus, 207-208. 
dan vida a una institucionalización de nivel supranacional sobre la materia (Naciones Unidas), así como a la primera Declaración Universal de Derechos Humanos (1948) ${ }^{65}$; esto tras las deplorables consecuencias de las dos guerras mundiales. La pregunta sobre los derechos humanos en la actualidad, ya iniciado el siglo XXI, se renueva entre otros frente al escenario del extenso desarrollo tecnocientífico. Las prerrogativas contempladas en esa declaración señera requieren de relecturas en donde conceptos como el ciberespacio, lo virtual o lo digital son parte de un léxico cotidiano que demanda también de un abordaje en términos de derechos. Por cierto, no solo se trata de una reinterpretación de los derechos ya existentes (la perspectiva hermenéutica, cómo no, presente), sino de visualizar la emergencia de nuevas prerrogativas para el habitante de la sociedad tecnológica de hoy, también como parte de un ejercicio interpretativo del nuevo contexto societal.

\section{Corolario: en torno a una declaración de derechos humanos en el ciberespacio}

En 1997 Robert Gelman propone una declaración sobre derechos humanos en el ciberespacio. Esta se sitúa como un primer esbozo e invita a los lectores del mundo a contribuir a su prosecución. Este documento se titula Draft Proposal: Declaration of Human Rights in Cyberspace $^{66}$. En lo que sigue, se destacarán algunos aspectos de esta declaración en relación con la perspectiva de los autores y tópicos abordados: Habermas desde el prisma discursivo y González desde la mirada del ciberhumanismo. Es interesante advertir no pocos puntos de confluencia entre las tres perspectivas.

65 Como se sabe, antecedentes modernos de esta declaración son la Declaración de Independencia de los Estados Unidos (1776) y la Declaración de los Derechos del Hombre y del Ciudadano de la Revolución Francesa (1789).

66 Esta declaración se encuentra disponible en el sitio: www.be-in.com/10/rightsdec.html. Se trata de un texto no editado, pero hecho público por su autor en 1997 como una invitación para continuar su construcción, a través del sitio señalado. 
Una primera parte está referido a las consideraciones preliminares incorporadas en el Preámbulo de la declaración, y de ella se pueden destacar los siguientes puntos:

- Primero, que tanto en su forma como en el contenido, esta declaración se asume como tributaria de la declaración de 1948, reafirma sus principios inspiradores y plantea la necesidad de remirar el tema de los derechos humanos en el nuevo escenario del ciberespacio ${ }^{67}$.

- Segundo, reafirma la necesidad de continuar pensando en el florecimiento de la condición humana en el mundo, un mundo ya no solo físico sino también virtual, cuando apunta al: «reconocimiento de que la Internet y sus redes relacionadas representan una vía abierta para las posibles mejoras de la condición humana, en particular la libertad, la justicia, la igualdad y la paz en todo el mundo» ${ }^{68}$.

- Empero lo anterior, se plantea también consciente de los peligros que este nuevo contexto ciberespacial puede acarrear, al sostener que: «la transición de una sociedad basada en la información hacia una basada en la propiedad crea una nueva estructura de poder que también tiene el potencial para oprimir y explotar a aquellos que carecen de acceso a la información y las herramientas de comunicación» ${ }^{69}$.

- Plantea la conectividad como un derecho y establece responsabilidades para los Estados, algo interesante en relación con la pregunta sobre a quién cabe garantizar prerrogativas en el ciberespacio. Al respecto, se lee: «es esencial, en una sociedad de la información global en red, que los derechos humanos fundamentales se extiendan para abrazar el acceso a la educación

67 Suñé sostendrá a este respecto que la cercanía de la propuesta de declaración de Gelman con la de 1948 es en parte meritoria -en la forma- y en parte demasiado tradicional -en el contenido-. Su análisis apunta a relevar la necesidad de «una declaración que sea también rompedora a nivel conceptual», Emilio Suñé, «Declaración de derechos del ciberespacio».

68 Robert Gelman, «Draft Proposal: Declaration of Human Rights in Cyberspace».

69 Robert Gelman, «Draft Proposal: Declaration of Human Rights in Cyberspace». 
y la conectividad, y que estos también deben ser protegidos por el Estado de Derecho» ${ }^{70}$.

- Sella un compromiso con la dignidad humana para quienes son parte de las comunidades en el ciberespacio, cuando sostiene: «que los pueblos de las diversas comunidades del ciberespacio reafirman su fe en los derechos fundamentales de la dignidad y el valor de la persona humana y la igualdad de derechos entre hombres y mujeres, y se han declarado resueltos a promover el progreso social y a elevar los niveles de vida en concordancia con una mayor libertad $\gg^{71}$.

Ahora bien, respecto de los derechos propiamente tales, en el apartado de artículos esta declaración propone consagrar, entre otros, las siguientes prerrogativas:

- Muy en concordancia con la premisa habermasiana en torno a la posibilidad potencial de todos para participar en procesos discursivos, en esta declaración se establece que: «las ideas y expresiones de todos los seres humanos merecen las mismas oportunidades para ser expresadas, consideradas y compartidas con otros, a discreción del emisor y el receptor, directa o indirectamente ${ }^{72}$. (artículo $\left.1^{\circ}\right)$.

- Se reconoce la trascendencia del ámbito ciberespacial a los márgenes nacionales: «Todos tienen derecho a todos los derechos y libertades proclamados en esta Declaración [...] Además, no se hará distinción alguna en función de la jurisdicción política o física, ni de su forma de acceso a la red» ${ }^{73}$. (Artículo $2^{\circ}$ ).

- La necesidad de regulación de los espacios virtuales. En virtud de lo expuesto en el presente artículo, se aboga por una extensión del prisma discursivo habermasiano a las interacciones en el 
ciberespacio, en complementación con un ciberhumanismo como el reseñado. Esto en concordancia con el siguiente artículo: «Mientras que todo el mundo tiene igual derecho a acceder a información o a entrar en las comunidades de la Red, la continuidad de la participación en esas comunidades deberá depender de un comportamiento ajustado a los estándares desarrollados y definidos dentro de esas comunidades $»^{74}$. (Artículo 6).

- El ciberespacio debe ser considerado mucho más que una mera plataforma de entretención o interacción puntual. La radicalidad de su fuerza e impacto en la vida de los seres humanos es tal que hoy prácticamente no resulta posible estar fuera de él, de una u otra forma, a través de diversos aparatos que llevan a estar viviendo permanente y simultáneamente en la dualidad física y virtual. En razón de esto, la reflexión filosófica, remite a la necesidad de regulación del ciberespacio en clave de derechos y deberes en él. La propuesta de Gelman utiliza incluso la denominación «orden social» para abordar el punto. Así se lee: «Toda persona tiene derecho a un orden social en el ciberespacio en el que los derechos y libertades proclamados en esta Declaración se hagan plenamente efectivos ${ }^{75}$. (Artículo $22^{\circ}$ ).

Ahora, en cuanto a las aportaciones de Suñé, como se señaló anteriormente, este autor propone también una Declaración de Derechos del Ciberespacio, con ocasión de los sesenta años de la Declaración Universal de 1948. Su texto es bastante similar al de Gelman, aunque intenta marcar distancias con este. Básicamente, sus aspectos más distintivos estarían en dos frentes. Por una parte, avanza en términos de mayores niveles de concreción en cuanto a instancias específicas por medio de las cuales hacer frente a diferentes problemáticas, dilemas e inquietudes que despierta el ciberespacio. Como ya se mencionó a este respecto, propone 
concretamente entidades como: un Ombudsman del Ciberespacio y un Tribunal de Derechos en el Ciberespacio o la configuración de un poder constituyente en dicha esfera ${ }^{76}$.

Por otra, identifica y propone un conjunto de derechos más exhaustivo y preciso, entre los cuales destacan: prohibición de monopolios y oligopolios de información, derecho al Habeas Data, protección de menores, protección de la dignidad de la persona, libertad de trabajo y comercio en el ciberespacio, protección del patrimonio cultural inmaterial, derecho ciudadano a la relación telemática con los poderes públicos ${ }^{77}$.

Finalmente, al momento del cierre son numerosas las ideas que emergen para continuar profundizando esta reflexión, especialmente habida cuenta de lo nuevo de este escenario ciberespacial para el ser humano. Teniendo en cuenta las limitaciones propias de un texto en formato de artículo, como también en concordancia con los objetivos del mismo, solo es posible situar estas líneas como una invitación a continuar la reflexión. Como podrá observar el lector, el presente artículo ha ofrecido un conjunto de ideas para el debate, muchas de ellas más bien conformadas como preguntas que como respuestas. Y es así porque se trata de una temática emergente y en pleno desarrollo. Empero si tuviese que resaltarse el valor de este proceder, bien puede decirse que se trata de preguntas que invitan a continuar la reflexión, en vez de respuestas que pretendan clausurarla.

\section{Bibliografía}

Bustamante, Javier. «Derechos humanos en el ciberespacio». En Derechos Humanos: La condición humana en la sociedad tecnológica. Editado por Graciano González, 164-182. Madrid: Tecnos, 1999. 
Bustamante, Javier. «Hacia la cuarta generación de derechos humanos: repensando la condición humana en la sociedad tecnológica». Revista Iberoamericana de Ciencia, Tecnología, Sociedad e Innovación 1 (2001). Consultada en abril 23, 2015. www.oei. es/revistactsi/numero1/bustamante.htm

Bustamante, Javier. "Los derechos humanos de cuarta generación y sus implicaciones en la sociedad contemporánea», 2012. Consultada en enero 18, 2016. www. academia.edu/4483700/Los_derechos_humanos_de_cuarta_generaci\%C3\%B3n_y_sus_implicaciones_en_la_sociedad_contempor\%C3\%A1nea_2012_.

Bustamante, Javier «¿̇Qué puede esperar la democracia de internet? Una reflexión sobre la crítica de Langdon Winner al poder político transformador de la tecnología». Argumentos de razón técnica 7 (2004): 13-49. Consultada en julio 22, 2015. http://institucional.us.es/revistas/argumentos/7/art_1.pdf.

Cardwell, Donald. Historia de la tecnología. Madrid: Alianza, 1996.

Cortina, Adela. Ciudadanos del mundo. Hacia una teoría de la ciudadanía. Madrid: Alianza, 1999.

Cortina, Adela. Ética sin moral. Madrid: Tecnos, 2000.

Cortina, Adela. La Escuela de Fráncfort: crítica y utopía. Madrid: Síntesis, 2008.

Galzacorta, Íñigo; Ceberio, Iñaki y Aguirre, Javier. Diseñando el futuro. Reflexiones desde la filosofía. Madrid: Plaza y Valdés, 2011.

Gelman, Robert. «Draft Proposal: Declaration of Human Rights in Cyberspace», 1997. Texto no editado. Consultada en mayo 25, 2015. www.be-in.com/10/rightsdec.html.

González, Graciano. Ciberhumanismus. Una ética para el habitante de la sociedad tecnológica. Sevilla: Doss, 2010. 
González, Graciano, coord. Derechos Humanos: La condición humana en la sociedad tecnológica. Madrid: Tecnos, 1999.

Habermas, Jürgen. Ciencia y técnica como ideología. Madrid: Tecnos, 2010.

Habermas, Jürgen. El futuro de la naturaleza humana ¿Hacia una eugenesia liberal? Barcelona: Paidós, 2002.

Habermas, Jürgen. Entre naturalismo y religión. Barcelona: Paidós, 2006.

Habermas, Jürgen. Facticidad y validez. Madrid: Trotta, 2008.

Habermas, Jürgen. La constelación posnacional. Barcelona: Paidós, 2000.

Habermas, Jürgen. La constitución de Europa. Madrid: Trotta, 2012.

Habermas, Jürgen. La inclusión del otro. Barcelona: Paidós, 2010.

Habermas, Jürgen. La reconstrucción del materialismo histórico. Madrid: Taurus, 1981.

Habermas, Jürgen. Más allá del Estado nacional. México: Fondo de Cultura Económica, 1998.

Llácer, Pilar. «Internet y derechos humanos: la libertad de expresión en el ciberespacio». En Derechos Humanos: La condición humana en la sociedad tecnológica, editado por Graciano González, 183-212. Madrid: Tecnos, 1999.

Lévy, Pierre. ¿Qué es lo virtual? Barcelona: Paidós, 1999.

Maceiras, Manuel. «Tecnociencia y política de derechos humanos». En Derechos Humanos: La condición humana en la sociedad tecnológica, editado por Graciano González, 97-130. Madrid: Tecnos, 1999.

Mansell, Robin. «Introduction. Human rights and equity in $\mathrm{Cy}$ berspace». En Human Rights in the Digital Age, editado por Andrew Murray y Mathias Klang, 1-10. London: The Glasshouse Press, 2009. 
Martínez de Pisón, José. «Las generaciones de derechos humanos». En Constitución y derechos fundamentales, coordinado por Jerónimo Betegón, Francisco Javier Laporta, Juan Ramón Páramo y Luis Prieto Sanchís, 409-435. Madrid: Centro de Estudios Constitucionales, 2004.

Morales, Paulina. «Hacia intervenciones sociales democratizantes: aportes desde el prisma discursivo de Jürgen Habermas». Trabajo Social, 83 (2012): 7-21.

Ortega y Gasset, José. Ensimismamiento y alteración. Meditación de la técnica y otros ensayos. Madrid: Alianza, 2014.

Sánchez, David. «Sobre el concepto de historización. Una crítica a la visión sobre las de-generaciones de derechos humanos». Praxis, 67 (2011): 9-22.

Smith, Marc y Kollock, Peter. Comunidades en el ciberespacio. Barcelona: UOC, 2003.

Suñé, Emilio. "Declaración de derechos del ciberespacio», 2008. Texto no editado. Consultada en mayo 28, 2015. http://190.7.110.123/pdf/7_convencionesDerechoInformatico/documentacion/conferencias/Los_Derechos_Humanos_en_el_Ciberespacio.pdf.

Villarroel, Raúl. Interesarse por la vida. Ensayos bioéticos y biopolíticos. Santiago: Universitaria, 2014.

Winner, Langdon. La ballena y el reactor. Una búsqueda de los límites en la era de la alta tecnología. Barcelona: Gedisa, 2008.

Enviado: 9 de marzo de 2017 Aceptado: 14 de mayo de 2017 